\title{
BMJ Open Understanding the impact of a residential housing programme for people living with HIV/AIDS: a realist evaluation protocol
}

\author{
Shaneice Fletcher-Hildebrand (D) , ${ }^{1}$ Hubert Alimezelli, ${ }^{2}$ Tracey Carr, ${ }^{2}$ \\ Karen Lawson, ${ }^{1}$ Anum Ali, $^{2}$ Gary Groot $^{3}$
}

To cite: Fletcher-Hildebrand S, Alimezelli H, Carr T, et al. Understanding the impact of a residential housing programme for people living with HIV/AIDS: a realist evaluation protocol. BMJ Open 2021;11:e044522. doi:10.1136/ bmjopen-2020-044522

- Prepublication history for this paper is available online. To view these files, please visit the journal online (http://dx.doi. org/10.1136/bmjopen-2020044522).

Received 08 September 2020 Revised 01 March 2021 Accepted 17 March 2021

Check for updates

(c) Author(s) (or their employer(s)) 2021. Re-use permitted under CC BY-NC. No commercial re-use. See rights and permissions. Published by BMJ.

${ }^{1}$ Psychology, University of Saskatchewan College of Arts and Science, Saskatoon, Saskatchewan, Canada ${ }^{2}$ Community Health and Epidemiology, University of Saskatchewan College of Medicine, Saskatoon, Saskatchewan, Canada ${ }^{3}$ Community Health and Epidemiology, University of Saskatchewan, Saskatoon, Saskatchewan, Canada

Correspondence to

Dr Gary Groot;

gary.groot@usask.ca

\section{ABSTRACT}

Introduction Housing instability and homelessness are significant barriers to medical treatment for people living with HIV/AIDS. For these individuals, lack of stable housing and stigma is associated with insufficient access to care, poor adherence to medication and higher cost burdens to the healthcare system. This protocol reports on the efforts to evaluate Sanctum V.1.0, a hospice and transitional care home for adults with HIV/AIDS in Saskatoon, Saskatchewan, Canada. The current project was developed out of a need to identify how Sanctum V.1.0 produces varying programme outcomes to assist in endeavours to replicate the programme in other geographic locations. Methods and analysis A realist evaluation will be conducted to explore how and why Sanctum V.1.0 is successful or unsuccessful, in which circumstances and for whom. Rather than explore the degree to which a programme is effective, realist evaluations seek to uncover mechanisms that explain processual links between programme inputs and outcomes. The completed first phase of the project involved the development of an initial realist programme theory. Phases 2 and 3 will consist of methods to test, refine and validate the initial theory using various data sources.

Ethics and dissemination Ethics approval was obtained from the institutional review board at the University of Saskatchewan on 2 July 2020. Results will be disseminated according to stakeholders' desires.

\section{INTRODUCTION}

Housing instability and homelessness are significant barriers to medical treatment for people living with HIV/AIDS (PLHIV). ${ }^{1-3}$ Although housing is a human right ${ }^{4}$ and a top service priority for PLHIV, ${ }^{5}$ obtaining stable, safe housing is challenging for these individuals. HIV-related stigma has prevented PLHIV from obtaining and maintaining safe places of residence. ${ }^{16}$ Qualitative accounts illustrate instances of property defacement, neighbourhood gossip and threatening letters tied to one's HIV status. ${ }^{16}$ Furthermore, PLHIV are often unemployed, have difficulty affording housing costs and, therefore, may be unable
Strengths and limitations of this study

- Realist evaluation allows for a comprehensive, contextual exploration of how and why a hospice and transitional care home for people living with HIV/ AIDS in Saskatchewan, Canada is successful or unsuccessful.

Depicting links between contexts, mechanisms and outcomes in the initial realist programme theory posed a challenge in phase 1 , although data collected from phases 2 and 3 may produce more nuanced connections.

- Including a patient partner as part of the research team in phase 2 will inform culturally appropriate data collection and dissemination strategies based on programme experience.

- The expected sample sizes for qualitative data are small, but align with realist modes of inference, and will be flexible to ensure theoretical saturation and adequate data to refine the initial realist programme theory.

to afford safe housing. ${ }^{7-12}$ PLHIV have also been denied housing due to their HIV status and related identities (eg, nonheteronormative sexual orientations). ${ }^{1}$ Feeling unsafe in a place of residence (eg, due to abusive relationships or drug activity) has resulted in housing instability for PLHIV. ${ }^{1}$

Lack of stable housing and HIV-related stigma is associated with poor access to care and adherence to medication. ${ }^{2}{ }^{13-15}$ While antiretroviral therapy (ART) is known to suppress the virus, thus reducing mortality and morbidity, it is more effective with greater adherence. ${ }^{16}$ PLHIV who are homeless engage in HIV care less than those who are housed ${ }^{13}$ and tend to have poorer physical and mental health and higher mortality rates, compared with those with stable housing. ${ }^{12-19}$ Among a sample of people living with AIDS, the 5-year survival rate following diagnosis was significantly higher for those with stable housing 
$(81 \%)$ than for those who were homeless $(67 \%) .{ }^{18}$ Similarly, in a sample of PLHIV, those who were homeless had a significantly higher mortality rate (27 times higher) than those who were housed. ${ }^{19}$ This highlights the need to provide PLHIV with supportive housing to improve their access and adherence to healthcare and bolster overall health.

Healthcare systems are also impacted by the housing status of PLHIV, as cost burdens tend to be higher when PLHIV are unstably housed. ${ }^{20-22}$ Unstably housed PLHIV in Vancouver, British Columbia were 1.87 times more likely to use the emergency department and 2.71 times more likely to be classified as nonurgent, compared to those with housing. ${ }^{23}$ Addressing unstable housing among this population could reduce costs to the healthcare system. Others have found similar results. ${ }^{9}{ }^{12} 23-25$

The beneficial effects of housing programmes for PLHIV are well established in the literature. These effects include increased chances of maintaining housing ${ }^{72627}$; increased adherence to ART, ${ }^{28}{ }^{29}$ thereby decreasing viral load and increasing CD4 count ${ }^{811262930}$; improved overall physical and mental health ${ }^{1227}$ and decreased risk of death and improved lifespan. ${ }^{18} 31$ Positive effects of residential programming also extend to the healthcare system, by decreasing emergency room visits and hospital admission rates. ${ }^{12} 2232$ The current paper will report on the efforts to evaluate a housing programme for PLHIV, including a summary of the completed phase and an overview of the next phases. The present project will explore why and how this specific programme functions to produce programme outcomes.

\section{The setting}

The programme under investigation is situated in Saskatoon, Saskatchewan, Canada. Saskatchewan currently has the highest provincial HIV diagnosis rate in Canada. ${ }^{33}$ In 2018, the national HIV diagnosis rate was 6.9 per 100 000 people, whereas the rate in Saskatchewan was 14.9 per 100000 people. ${ }^{33}$ Furthermore, the diagnosis rate in Saskatoon was one of the highest in Saskatchewan at 17.0 per 100,000 people. $^{34}$

Within this setting, it is crucial to discuss HIV/AIDS as part of an intersection between ethnicity, injection drug use and housing status. Indigenous people in Canada are disproportionately affected by HIV/AIDS. ${ }^{35}$ In 2014 , Indigenous persons accounted for approximately $16 \%$ of HIV/AIDS cases while comprising approximately $4 \%$ of the Canadian population. ${ }^{35-37}$ Disproportionate diagnosis is especially evident in Saskatchewan. Between 2009 and 2018, the proportion of new HIV diagnoses to Indigenous people ranged from $69 \%$ to $81 \%,{ }^{34}$ despite making up $16.3 \%$ of the provincial population in $2016 .^{38}$

Approximately $57 \%$ of HIV cases reported in Canada in 2018 included information about exposure. The top three exposure categories included: (a) gay, bisexual and other men who have sex with men $(41.4 \%)$, (b) heterosexual contact $(32.3 \%)$ and (c) injection drug use $(18.3 \%){ }^{33}$ Reported HIV cases are almost four times as likely to be linked with injection drug use in Saskatchewan compared with overall cases in Canada. ${ }^{34}$ Data on injection drug use prevalence are currently unavailable in Saskatchewan, however, data from a 2012 Canadian survey show that $43.9 \%$ of the sample from Saskatchewan reported illicit drug use at some point in their life (cocaine, speed, methamphetamine, hallucinogens, extasy, salvia and/or heroine). ${ }^{39}$ Programming for PLHIV in Saskatchewan needs to be sensitive to these demographic distinctions to best support these individuals.

\section{The intervention}

Sanctum Care Group is a nonprofit organisation in Saskatoon, Saskatchewan to support PLHIV who require assistance. The organisation operates under harm reduction and holistic care philosophies and takes a patientoriented approach to care. While four programmes are offered by Sanctum Care Group (see table 1), this evaluation focusses on Sanctum V.1.0, which provides supportive care (eg, subacute, rehabilitative), palliative/hospice care (eg, pain control, symptom management) and respite care. Staff also assist those with unstable housing in achieving housing stability following their stay. Most clients at Sanctum V.1.0 are Indigenous, unstably housed and have other mental and physical health conditions (J. Patrick, personal communication, 3 September 2020). These services are comparable to other programmes in Canada, such as the Dr Peter Centre in Vancouver, British Columbia and Bruce House in Ottawa, Ontario.

Table 1 Programmes offered at Sanctum 1.0

\begin{tabular}{ll}
$\begin{array}{l}\text { Sanctum Care Group } \\
\text { Programme }\end{array}$ & Description of Programme \\
\hline Sanctum 1.0 & $\begin{array}{l}\text { A HIV hospice and transitional care home for adults who are HIV positive and deemed as high- } \\
\text { risk due to such factors as unstable housing or substance addictions. }\end{array}$ \\
Sanctum 1.5 & $\begin{array}{l}\text { A prenatal care home for pregnant women who are HIV positive and deemed high risk. } \\
\text { Beehive }\end{array}$ \\
AART & $\begin{array}{l}\text { Apartments that Sanctum } 1.0 \text { residents can transition to after } 3 \text { months if they desire continued } \\
\text { supportive living. }\end{array}$ \\
& $\begin{array}{l}\text { A group of support workers who assist PLHIV who are admitted to the hospital or access } \\
\text { emergency rooms. }\end{array}$ \\
\hline
\end{tabular}

PLHIV, people living with HIV/AIDS. 


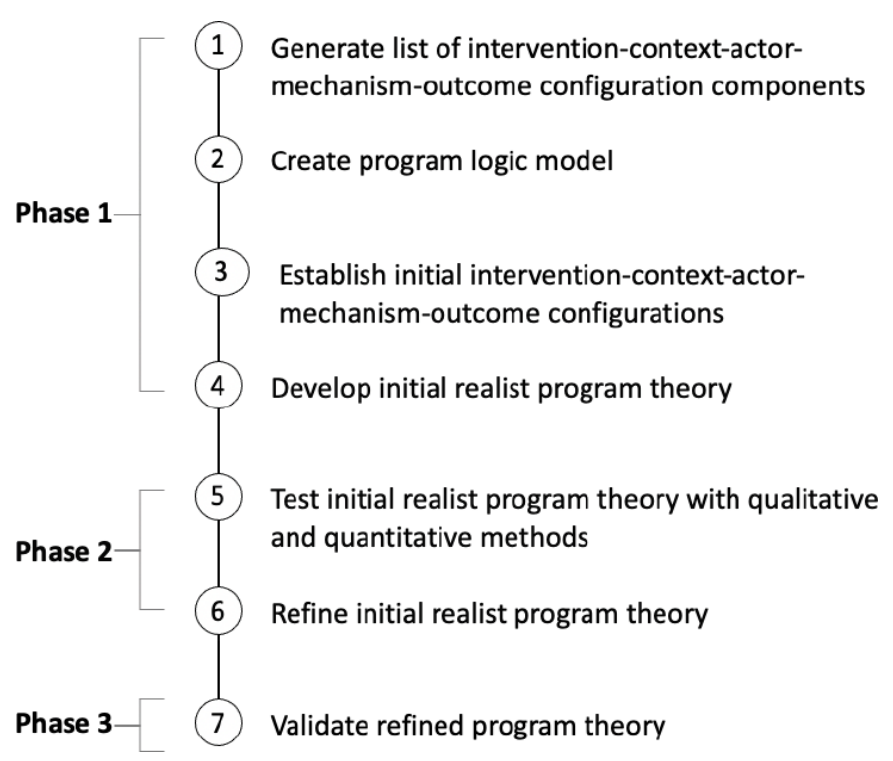

Figure 1 Research process informed by Pawson and Tilley.

\section{Aim of the study}

The current study is focused on the development, refinement and initial validation of a programme theory for Sanctum V.1.0. Unpublished evaluations of Sanctum V.1.0 by the Saskatoon Health Region in 2016 and 2017 examined the extent to which desired outcomes were achieved but did not examine how the programme itself led to these outcomes. The current project was, therefore, developed out of a need to identify how Sanctum V.1.0 leads to successful or unsuccessful outcomes and to assist in endeavours to replicate the programme in other geographic locations. A realist evaluation is the most suitable approach, as they explore: 'What works for whom in what circumstances and in what respects, and how? ${ }^{40}$ While group-based programming for PLHIV has been researched in Africa using realist approaches, ${ }^{41-43}$ the programmes were not housing based. Moreover, this study will be the first to report a realist evaluation of a residential programme for PLHIV in Canada. We aim to address the following research question: How and why is Sanctum V.1.0 successful or unsuccessful for which clients and in which circumstances?

\section{METHODS AND ANALYSIS \\ Research design}

Three research phases will contribute to creating, testing and refining a programme theory (see figure 1). This is an iterative process, and resulting theories are provisional. ${ }^{40}$ While phase 1 was completed in 2020, phases 2 and 3 will begin in the near future. Realist programme theories are formulated by constructing context-mechanism-outcome configurations (CMOC), which indicate how mechanisms influence outcomes for certain individuals in certain contexts. ${ }^{44}$ Contexts are conditions in which a programme is embedded that trigger and/ or modify mechanisms. ${ }^{45}$ In realist evaluation, mechanisms are a combination of programme resources and programme participants' reasoning. ${ }^{44}{ }^{46}$ Mechanisms explain how things work in a causal manner by revealing why and how one event leads to another, opposed to simply demonstrating relationships between variables. Thus, mechanismic explanations move beyond black box explanations that are merely concerned with the degree to which programmes produce outcomes. ${ }^{44} 4748$ Mechanisms are usually unobservable, change in response to contextual conditions and are means by which outcomes are produced. ${ }^{4649}$ Outcomes may be intended or unintended and short term, intermediate term or long term. ${ }^{45}$

Researchers have proposed adaptations to CMOCs by adding intervention and actor components, resulting in an intervention-context-actor-mechanism-outcome configuration (ICAMOC) ${ }^{50}$ Presently, the three central care types offered by Sanctum V.1.0 represent the intervention, and actors refer to specific programme clients. This configuration illustrates how interventions are expected to trigger mechanisms for specific actors, within certain contexts, which is proposed to produce outcomes. ${ }^{50}$ This approach is advantageous, for it speaks to the "what works for whom ${ }^{44}$ aspect of realist evaluation inquiry and makes programme resources more explicit. ${ }^{50}$ Overall, ICAMOCs provide a more nuanced, comprehensive representation of components that contribute to programme success or nonsuccess.

After ICAMOC components are identified, two modes of inference are used to test knowledge of real but fallible mechanisms: abduction and retroduction. ${ }^{51}$ Abduction is a process through which a set of concrete events or ideas are recontextualised through creative and imaginative approaches. ${ }^{51}$ Thus, a frequent step in realist evaluations is to come up with a theory (eg, based on hunches from the literature) about generative mechanisms driving programme outcomes. Retroduction is a process to determine what internal features characterise a phenomenon. ${ }^{51}$ Currently, this entails determining what it is about the programme that is constitutive of successful and/or unsuccessful outcomes. The following sections outline the methods chosen for constructing and testing a programme theory.

\section{Phase 1: initial realist programme theory development}

Realist programme theories outline which contexts trigger mechanisms that produce certain outcomes. ${ }^{44}$ The purpose of establishing an initial realist programme theory (IRPT) is to eventually test and refine the theory. Phase 1 consisted of four steps outlined in figure 1 . Deductive content coding was used to identify ICAMOC components from four data sources (discussed below). Outcomes were coded as Sanctum V.1.0 goals and research results that were relevant to Sanctum V.1.0, mechanisms were coded when an explanatory factor (eg, programme resource or participant reasoning) could be tied to an outcome, and contexts were indicated when phrases described conditions that could prompt or alter the mechanism(s). Intervention components were identified as the three main care types offered at Sanctum 
V.1.0, and the actors represented Sanctum V.1.0 clients. A team member who was familiar with the literature on residential programming for PLHIV approved the list before moving onto the next steps.

First, a literature search was conducted in June 2020 to identify research involving programmes with residential components for PLHIV. Articles were eligible if they were published in English, included study participants who were PLHIV, and the study reported on the impacts of a residential programme. Three searches were completed using the Medline database and the following key terms: HIV, residential or housing facilities/programmes, homeless persons, drug use and programme evaluation. Four out of 43 resulting articles were eligible. More literature was needed to better understand ICAMOC components; thus, we completed an exploratory Google Scholar search and coded articles until we felt there was enough information to construct an IRPT, which is consistent with abduction. ${ }^{51}$ Four new articles were gathered from this search, resulting in a total of eight articles.

Second, a review of relevant programme documents was completed. Previous unpublished evaluations of Sanctum V.1.0 included resident demographics (context); qualitative and quantitative data indicating why Sanctum V.1.0 is valuable to residents (mechanisms) and outcomes related to medication adherence and health status. Six patient narratives generated by programme staff outlined circumstances surrounding the cases (contexts), client quotes describing what they liked about the programme (mechanisms) and general health outcomes for the individual. A client expectation form included harm-reduction expectations (context) and stated a programme goal (safe environment).

Third, detailed notes from a 1-hour meeting with Sanctum Care Group's executive director included organisational contexts (eg, healthcare approaches), what makes Sanctum V.1.0 successful (contexts and mechanisms), what might lead to unsuccessful outcomes (eg, clients who do not adhere to organisational policies), what the programme offers clients (intervention) and who attends Sanctum V.1.0 (actors). Finally, a review of Sanctum V.1.0's website verified previously identified ICAMOC components and revealed programme goals (outcomes).

Programmes are said to exist within social systems. ${ }^{40}$ Therefore, it is important to consider contexts and mechanisms that reside within varying levels of social reality. A social-ecological lens was applied, in which contexts and mechanisms were organised into micro, meso and macro levels. Individual level factors were deemed microlevel, while mesolevel elements represented interpersonal and organisational factors, and macrolevel elements were community based. This strategy will enable us to discuss the findings in relation to levels of social systems. Outcomes were labelled short term, intermediate term or long term. Table 2 lists CMOC components.

Next, we created a programme logic model (see figure 2), which illustrates how programme components are linked with programme outcomes. ${ }^{52} \mathrm{CMOC}$ narratives were then constructed to connect contexts, mechanisms and outcomes organised in the first two steps. Based on information gathered from the first step, three main social science theories were chosen to guide development of CMOCs, including empowerment theory, ${ }^{53} 54$ self-efficacy theory $^{55}$ and the information-motivation-behaviour model. ${ }^{5657}$ The CMOCs needed to be condensed to form an IRPT. The first column of intermediate outcomes in the programme logic model (see figure 2) were most representative of Sanctum V.1.0's main behavioural outcomes; thus, CMOCs were organised accordingly into three streams. The short-term, more cognitive, outcomes were translated into microlevel contexts, while the second column of intermediate outcomes was converted into outcomes in the CMOCs. Long-term outcomes are depicted as overarching programme goals expected to result from all CMOC streams. Intervention and actor components were added to the diagram, so that the IRPT reflected all ICAMOC components (see figure 3).

Phase 2: realist programme theory testing and refinement Patient and public involvement

A patient partner from Sanctum V.1.0 will be included as part of the evaluation team in phases 2 and 3 to inform data collection strategies, participant recruitment, data interpretation and dissemination of findings. A patientdriven approach is crucial, as the client will be able to inform evaluators about appropriate research methods and language to use considering the vulnerable population. The following section outlines phases that have not yet been completed (see figure 1) and will be informed by the outcomes of phase 1 .

\section{Phase 2 methods}

A mixed-method design will be employed by collecting and triangulating quantitative and qualitative data to test the programme theory. Although Sanctum V.1.0 mainly serves Indigenous clients, data collection will be open to Sanctum V.1.0 clients with any ethnic identity. Quantitative data will be collected from all Sanctum V.1.0 records, including total and annual summary data on admissions, programme completions, drop outs and staffing (a measure of resident support). Medication adherence will also be recorded, as Sanctum V.1.0 keeps individual charts that track medication use. This information will be analysed using descriptive statistics in SPSS (V.25) to provide relevant contextual information such as demographics and speak to the medication adherence outcome in the IRPT.

Qualitative data will be gathered from multiple stakeholders holding diverse expertise and perspectives related to contexts, mechanisms and/or outcomes. ${ }^{40}{ }^{44}$ Using convenience sampling, we expect to conduct 10 in-depth realist interviews with Sanctum Care Group board members and staff and 10 with Sanctum V.1.0 clients, which aligns with realist data collection strategies. ${ }^{44}$ To explore potentially unsuccessful outcomes, we aim to 
Table 2 List of initial contexts, mechanisms and outcomes gleaned from phase 1 data sources

\begin{tabular}{|c|c|c|c|}
\hline \multirow[t]{2}{*}{ Element } & \multicolumn{3}{|l|}{ Social-ecological model level } \\
\hline & Micro & Meso & Macro \\
\hline Contexts & $\begin{array}{l}\text { Demographics (eg, HIV/AIDS } \\
\text { status, Indigenous ethnicity, } \\
\text { unstable housing, criminal justice } \\
\text { involvement, low income, low } \\
\text { education level) }\end{array}$ & $\begin{array}{l}\text { Positive interactions with staff and } \\
\text { peer mentors } \\
\text { Harm reduction philosophy } \\
\text { Patient-oriented approach } \\
\text { Focus on clients' control over their } \\
\text { health and end-of-life dignity } \\
\text { Holistic care plans } \\
\text { - Non-judgmental environment }\end{array}$ & $\begin{array}{l}\text { HIV-related stigma } \\
\text { Community partnerships } \\
\text { Funding } \\
\text { Geographic location of } \\
\text { residence (near multiple } \\
\text { resources) }\end{array}$ \\
\hline Mechanisms & $\begin{array}{l}\text { Comfort } \\
\text { Empowerment } \\
\text { Stability } \\
\text { - Motivation } \\
\text { Self-efficacy } \\
\text { Self-worth } \\
\text { - Belonging } \\
\text { Alleviation from chaotic lifestyle } \\
\text { Stress reduction } \\
\text { - Safety } \\
\text { - Independence } \\
\text { Feelings unsafe } \\
\text { Feeling isolated }\end{array}$ & $\begin{array}{l}\text { Trusting relationships } \\
\text { Supportive relationships } \\
\text { Social integration }\end{array}$ & $\begin{array}{l}\text { Alleviation from social } \\
\text { inequity in the community }\end{array}$ \\
\hline
\end{tabular}

\begin{tabular}{|c|c|c|c|}
\hline \multirow[t]{2}{*}{ Element } & \multicolumn{3}{|l|}{ Outcome level } \\
\hline & Short-term & Intermediate-term & Long-term \\
\hline Outcomes & $\begin{array}{l}\text { Knowledge of safe injection drug } \\
\text { use } \\
\text { Knowledge of wraparound support } \\
\text { services } \\
\text { Knowledge of health treatments } \\
\text { Increased sense of belonging } \\
\text { Increased sense of safety }\end{array}$ & $\begin{array}{l}\text { Practice safe injection drug use, } \\
\text { thereby minimising risky behaviour } \\
\text { Confidence and empowerment } \\
\text { to manage conditions, thereby } \\
\text { improving autonomous self-care } \\
\text { Adherence to medical treatments, } \\
\text { thereby improving medical indicators } \\
\text { of health }\end{array}$ & $\begin{array}{l}\text { Improved mental and } \\
\text { physical health } \\
\text { Increased quality of life } \\
\text { Decrease in hospital } \\
\text { readmissions and } \\
\text { emergency room visits } \\
\text { Decrease cost burden on } \\
\text { healthcare system }\end{array}$ \\
\hline
\end{tabular}

recruit at least five individuals who have dropped out of the programme. Sample size will be flexible in order to reach theoretical saturation ${ }^{58} 59$ and ensure that there is enough information to revise the IRPT.

The interviews will be semistructured and the topic will be the realist programme theory. ${ }^{44} 60$ These interviews can be described as theory-refining, ${ }^{60}$ as the purpose is to clarify and improve the IRPT. Interviewers will be trained to use the teacher-learner process, in which the interviewer teaches the interviewee the Sanctum V.1.0 IRPT, and, in turn, the interviewee will reveal their ideas about how the programme functions. ${ }^{45}$ Questions suggested by Mukumbang and colleagues at this stage include those about programme resources, constraints and opportunities. ${ }^{61}$ Additionally, the authors suggest asking programme clients about how they make decisions regarding certain outcomes (eg, adherence to medical treatment). ${ }^{61}$ When creating the interview guide, we will include our explanation of each stream in the IRPT and follow-up with the participant by asking how they perceive Sanctum V.1.0 functions. We will include prompts to elicit information about barriers and facilitators to achieving programme goals and inquire about clients' personal journeys regarding each ICAMOC. ${ }^{61}$ Interviews will be co-led by an evaluator and patient partner.

Using convenience sampling, we will also complete two sharing circles with approximately five clients each on the topic of the IRPT. Sharing circles are a culturally appropriate qualitative group method for participants who are Indigenous. ${ }^{62-64}$ Sharing circles are an open-ended storytelling method that aims to give voice to those who are marginalised and is associated with healing. ${ }^{62} 63$ The purpose is to generate knowledge that can be used to address the needs of Indigenous communities ${ }^{64}$ such as identifying which Sanctum V.1.0 activities and resources are effective for clients and why.

There are important differences between sharing circles and other qualitative group methods, such as focus groups. 


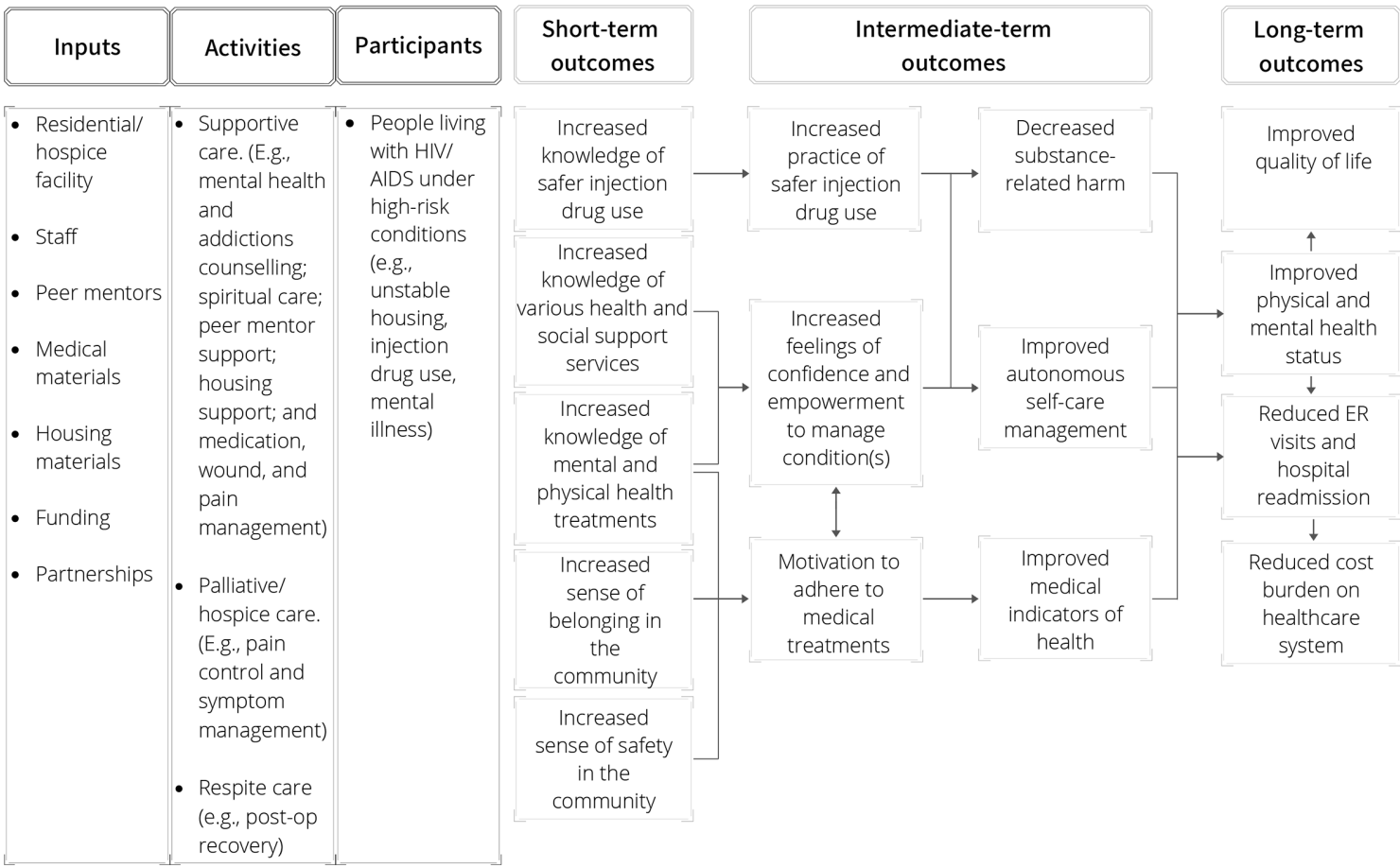

Figure 2 Sanctum 1.0 programme logic model

Practically, focus groups are often $90-120 \mathrm{~min},{ }^{65}$ whereas sharing circles are not bound by time. ${ }^{6364}$ Furthermore, a moderator or facilitator leads focus groups, while a cultural person or elder leads sharing circles. ${ }^{62} 6465$ Cultural persons and elders have expertise in cultural protocol and may have meaningful relations with participants who are encouraged, for they promote comfort and trust. ${ }^{6264}$ In the present evaluation, an elder who is known to the Sanctum V.1.0 community will be hired to lead the sharing circle. There are also procedural differences. Cultural protocols dictate how

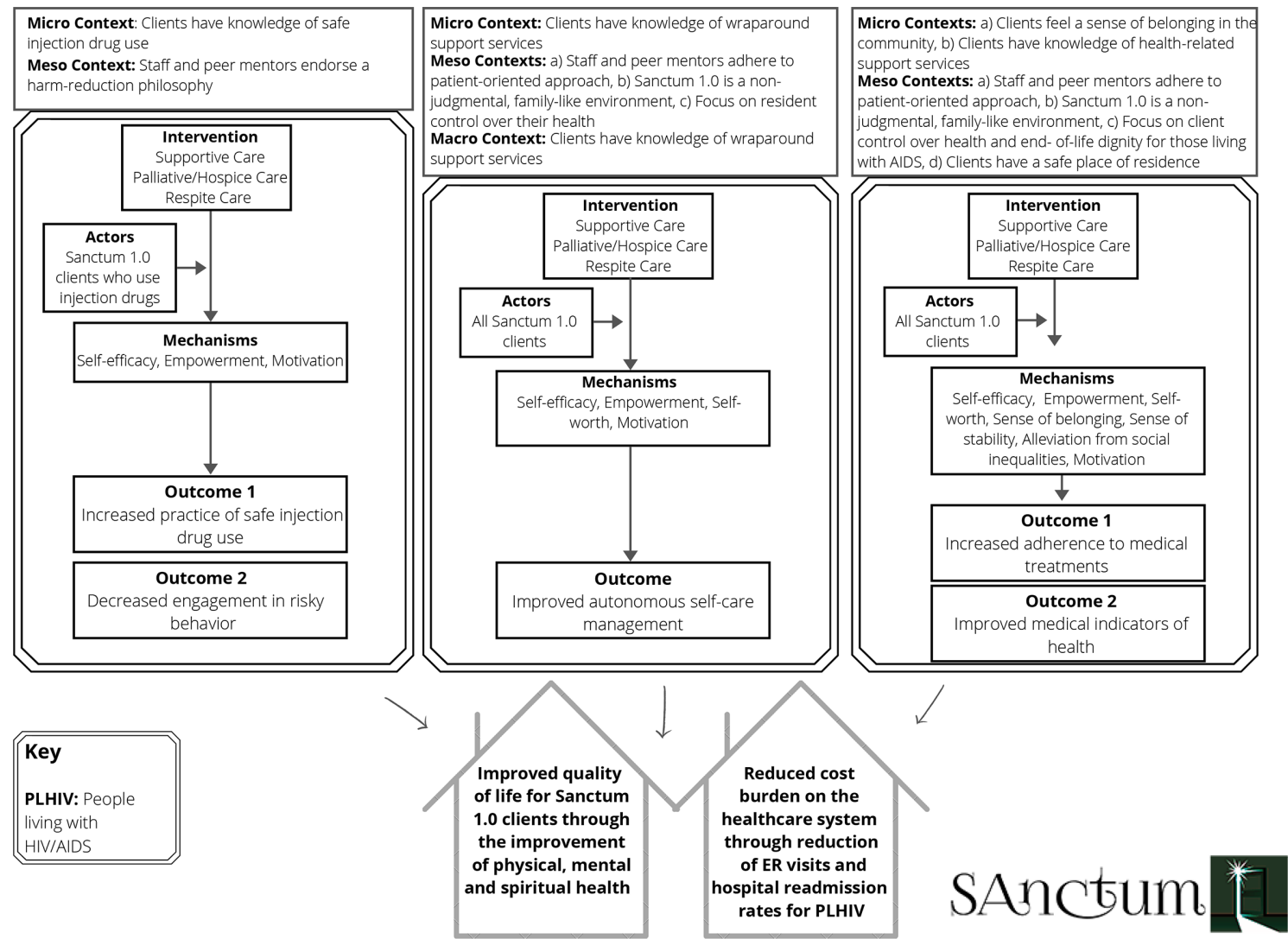

Figure 3 Sanctum 1.0 initial realist programme theory. 
sharing circles begin and end (eg, an elder may begin by acknowledging the creator and ancestors with a traditional prayer), which is not common in focus groups. ${ }^{63-66}$ Within a sharing circle, elders will pose an open-ended question to individuals, who respond one-by-one without interruption from others, ${ }^{6364}$ while focus group moderators usually pose questions and anyone can respond in any order. ${ }^{656}$ Interviews and sharing circles will be recorded and transcribed for analysis.

There is no method of analysis that is favoured for qualitative realist data. ${ }^{40}$ Instead, evaluators must choose a method that will best illustrate IRPT acceptability. Strategies for realist qualitative data will be used to guide analysis. ${ }^{6768}$ Transcripts will be coded using NVivo (V.1.0) according to current recommendations. ${ }^{68}$ Nodes (themes) will be created to represent ICAMOCs from the IRPT. Child nodes (subthemes) will be added to each node to symbolise the data source (eg, literature, programme documents, stakeholder meeting, website). Data from phase 2 will be added to the existing nodes. Memos will be used to document team decisions that were made to refine the IRPT.

Multiple procedures will be followed to ensure that the evaluation is conducted rigorously. Information regarding five indicators of administrative data quality outlined by Henson will be recorded in order to be transparent about the data from Sanctum V.1.0 records: completeness, timeliness, valid representativeness, consistency and integrity. ${ }^{69}$ Data quality will be commented on when the findings are reported. Once qualitative data are transcribed, the interviewer will scan the transcript for accuracy. To assess trustworthiness and rigour of the coded qualitative data, member checks will be completed by a team member and a patient partner. When analysis is complete, programme stakeholders will have a chance to review the interpreted results in phase 3 .

\section{Phase 3: realist programme theory validation}

To validate the revised programme theory, meetings with Sanctum Care Group board members, staff and patient partners will take place. The purpose is to ensure that the resulting, provisional theory is an appropriate representation of Sanctum V.1.0. Stakeholders will provide feedback regarding how accurately the theory reflects their perceptions of the programme and the IRPT will be refined if necessary. If required, child nodes will be created to represent refined elements within the respective ICAMOC node. ${ }^{67}$ Memos will be attached to these child nodes to document the decision-making that occurred within the theory validation meeting. ${ }^{6768}$ All results from phase 2 will be reported according to RAMSES II guidelines for realist evaluation. ${ }^{70}$

\section{Ethics and dissemination}

The current project obtained ethical approval from the University of Saskatchewan's research ethics board on 2 July 2020. Each researcher completed online ethics training based on Canada's tricouncil policy guidelines for conducting research with humans. Verbal and/or written consent will be obtained prior to all data collection and identifying data will be kept confidential. A partnership agreement between
Sanctum Care Group and the evaluation team was signed prior to beginning the project, outlining project objectives, consent procedures, expected time contributions, data ownership and the publication processes. The results of this study will be disseminated according to stakeholders' desires.

\section{DISCUSSION}

The aim of this evaluation is to establish a refined programme theory describing how and why Sanctum V.1.0 produces successful and/or unsuccessful outcomes for PLHIV in certain contexts. Realist evaluations are highly suitable for this type of inquiry, as they elicit testable, explanatory programme theories. The generative view of causation guides the realist evaluation process by focusing on creating programme theories that exhibit the ways in which underlying mechanisms contribute to programme outcomes.

There are three main advantages to the current project. First, realist evaluations move away from black box programme explanations and toward detailed accounts of why and how a programme operates. ${ }^{4144871}$ Second, the evaluation team is a multidisciplinary group with roots in psychology, programme evaluation and community health and epidemiology. Others explain multidisciplinary teams as favourable, for it helped them choose guiding substantive theories. ${ }^{69}$ Presently, a team with varied expertise will be valuable for uncovering different theories present in participant accounts that would have been missed otherwise. Second, a patient-driven approach will be taken by including a programme client on the evaluation team. Their experience will educate the evaluators on appropriate data collection methods and language use. Furthermore, their assistance synthesising data will help interpret and uncover programme theories.

Realist evaluations are not without challenges. ${ }^{72}$ First, there are no prescriptive steps for conducting realist evaluations. ${ }^{40} 73$ In the current evaluation, there were uncertainties about how to transform multiple ICAMOCs into a single depiction of a theory, especially as IRPTs have been represented in various ways. ${ }^{43}{ }^{74-76}$ Choosing to focus on three central Sanctum V.1.0 outcomes in the programme logic model helped organise the hypothesised links between contexts, mechanisms and outcomes. Without prescribed guidelines, decisions also had to be made regarding data collection and analysis. In line with others' suggestions, methods were chosen that would aid in revising the IRPT. ${ }^{40}$

Second, time is a practical challenge when pursuing realist evaluations. ${ }^{72}$ For example, the iterative nature of realist evaluations may inhibit forward movement in the evaluation. ${ }^{40} \mathrm{In}$ the current study, this may be challenging if crucial ICAMOCs were missed in phase 1 . However, multiple data sources were used to inform the IRPT, and feedback was obtained from the multidisciplinary team. Additionally, the refined programme theory will be informed by the patient partner and validated by stakeholders in phases 2 and 3 .

This evaluation will contribute to Sanctum Care Group's desire to extend their services to other communities in need of HIV/AIDS residential programming. With a programme theory, staff and board members will gain knowledge of 
contexts that are thought to generate mechanisms that foster successful outcomes. The contribution to realist evaluation literature is twofold. First, the study will provide preliminary evidence of a residential programme theory for PLHIV. Although others have completed work on group-based programming for PLHIV in Africa, ${ }^{41-43}$ the present evaluation will add by focusing on housing needs for PLHIV in Saskatchewan, where most PLHIV are Indigenous. Second, this protocol has implications for using programme logic models to create IRPTs. This strategy is not common in realist evaluations, ${ }^{77}$ yet it was useful for establishing outcome pathways, and provided the basis for creating the IRPT. As social programmes exist within varying layers of social reality, ${ }^{44}$ realist programme theories are key to uncovering the essence of programmes and, thus, enabling service providers to make informed decisions that suit the needs of their population. Unique strategies should continue to be shared in the realist research community that may improve the use of realist evaluations for programme staff, practitioners and policy makers.

Acknowledgements Our team would like to thank Sanctum Care Group staff and clients for working closely with us to establish a realist evaluation plan for Sanctum 1.0. As well, we are extremely grateful for the time, knowledge, and insight provided by Sanctum Care Group's executive director, Katelyn Roberts.

Contributors SF-H created the initial realist program theory and wrote the protocol manuscript. HA led the development of the initial grant, supervised the student, co-developed, reviewed and commented on the manuscript. TC assisted with the development of the initial grant proposal and reviewed and commented on the manuscript. KL supervised the student and reviewed and commented on the protocol manuscript. AA organised team meetings, coordinated the patientoriented research training and reviewed and commented on the manuscript. GG is the principal investigator of the initial grant proposal, supervised the student and reviewed and commented on the protocol manuscript.

Funding The present study is funded by Canadian Institutes of Health Research grant number 425031 .

Competing interests None declared.

Patient and public involvement Patients and/or the public were involved in the design, or conduct, or reporting, or dissemination plans of this research. Refer to the Methods section for further details.

Patient consent for publication Not required.

Provenance and peer review Not commissioned; externally peer reviewed.

Open access This is an open access article distributed in accordance with the Creative Commons Attribution Non Commercial (CC BY-NC 4.0) license, which permits others to distribute, remix, adapt, build upon this work non-commercially, and license their derivative works on different terms, provided the original work is properly cited, appropriate credit is given, any changes made indicated, and the use is non-commercial. See: http://creativecommons.org/licenses/by-nc/4.0/.

\section{ORCID iD}

Shaneice Fletcher-Hildebrand http://orcid.org/0000-0002-4076-6989

\section{REFERENCES}

1 Chambers LA, Greene S, Watson J, et al. Not just "a roof over your head": the meaning of healthy housing for people living with HIV. Housing, Theory and Society 2014;31:310-33.

2 Milloy M-J, Kerr T, Bangsberg DR, et al. Homelessness as a structural barrier to effective antiretroviral therapy among HIVseropositive illicit drug users in a Canadian setting. AIDS Patient Care STDS 2012;26:60-7.

3 Sprague C, Simon SE. Understanding HIV care delays in the US South and the role of the social-level in HIV care engagement/ retention: a qualitative study. Int J Equity Health 2014;13:28.

4 United Nations. The right to adequate housing, 2014. Available: https://www.ohchr.org/documents/publications/fs21_rev_1_housing_ en.pdf [Accessed 22nd Jul 2020].
5 Lennon CA, Pellowski JA, White AC, et al. Service priorities and unmet service needs among people living with HIV/AIDS: results from a nationwide interview of HIV/AIDS housing organizations. AIDS Care 2013:25:1083-91.

6 Greene S, Tucker R, Rourke SB, et al. "Under My Umbrella": the housing experiences of HIV positive parents who live with and care for their children in Ontario. Arch Womens Ment Health 2010;13:223-32.

7 Dasinger LK, Speiglman R. Homelessness prevention: the effect of a shallow rent subsidy program on housing outcomes among people with HIV or AIDS. AIDS Behav 2007;11:128-39.

8 Hawk M, Davis D. The effects of a harm reduction housing program on the viral loads of homeless individuals living with HIV/AIDS. AIDS Care 2012;24:577-82.

9 Kidder DP, Wolitski RJ, Royal S, et al. Access to housing as a structural intervention for homeless and unstably housed people living with HIV: rationale, methods, and implementation of the housing and health study. AIDS Behav 2007;11:S149-61.

10 Rourke SB, Bekele T, Tucker R, et al. Housing characteristics and their influence on health-related quality of life in persons living with HIV in Ontario, Canada: results from the positive spaces, healthy places study. AIDS Behav 2012;16:2361-73.

11 Towe VL, Wiewel EW, Zhong Y, et al. A randomized controlled trial of a rapid Re-housing intervention for homeless persons living with HIV/ AIDS: impact on housing and HIV medical outcomes. AIDS Behav 2019;23:2315-25.

12 Wolitski RJ, Kidder DP, Pals SL, et al. Randomized trial of the effects of housing assistance on the health and risk behaviors of homeless and unstably housed people living with HIV. AIDS Behav 2010;14:493-503.

13 Aidala AA, Wilson MG, Shubert V, et al. Housing status, medical care, and health outcomes among people living with HIV/AIDS: a systematic review. Am J Public Health 2016;106:e1-23.

14 Logie $\mathrm{CH}$, Williams CC, Wang Y, et al. Adapting stigma mechanism frameworks to explore complex pathways between intersectional stigma and HIV-related health outcomes among women living with HIV in Canada. Soc Sci Med 2019;232:129-38.

15 Palepu A, Milloy M-J, Kerr T, et al. Homelessness and adherence to antiretroviral therapy among a cohort of HIV-infected injection drug users. J Urban Health 2011;88:545-55.

16 Altice F, Evuarherhe O, Shina S, et al. Adherence to HIV treatment regimens: systematic literature review and meta-analysis. Patient Prefer Adherence 2019;13:475-90.

17 Thakarar K, Morgan JR, Gaeta JM, et al. Homelessness, HIV, and incomplete viral suppression. $J$ Health Care Poor Underserved 2016;27:145-56.

18 Schwarcz SK, Hsu LC, Vittinghoff E, et al. Impact of housing on the survival of persons with AIDS. BMC Public Health 2009;9:220.

19 Spinelli MA, Hessol NA, Schwarcz S, et al. Homelessness at diagnosis is associated with death among people with HIV in a population-based study of a US City. AIDS 2019;33:1789-94.

20 Basu A, Kee R, Buchanan D, et al. Comparative cost analysis of housing and case management program for chronically ill homeless adults compared to usual care. Health Serv Res 2012;47:523-43.

21 Dodd SJ, Ruffins J, Arzola D. Improving health while saving money: lessons learned from a supportive housing program for young adults with HIV. Sex Res Soc Policy 2018;15:163-71.

22 Holtgrave DR, Wolitski RJ, Pals SL, et al. Cost-Utility analysis of the housing and health intervention for homeless and unstably housed persons living with HIV. AIDS Behav 2013;17:1626-31.

23 Parashar S, Chan K, Milan D, et al. The impact of unstable housing on emergency department use in a cohort of HIV-positive people in a Canadian setting. AIDS Care 2014;26:53-64.

24 Fairbairn N, Milloy M-J, Zhang R, et al. Emergency department utilization among a cohort of HIV-positive injecting drug users in a Canadian setting. J Emerg Med 2012;43:236-43.

25 Kendall CE, Boucher LM, Mark AE, et al. A cohort study examining emergency department visits and hospital admissions among people who use drugs in Ottawa, Canada. Harm Reduct $J$ 2017;14:16.

26 Buchanan D, Kee R, Sadowski LS, et al. The health impact of supportive housing for HIV-positive homeless patients: a randomized controlled trial. Am J Public Health 2009;99 Suppl 3:S675-80.

27 Bean KF, Shafer MS, Glennon M. The impact of housing first and peer support on people who are medically vulnerable and homeless. Psychiatr Rehabil J 2013;36:48-50.

28 Parashar S, Palmer AK, O'Brien N, et al. Sticking to it: the effect of maximally assisted therapy on antiretroviral treatment adherence among individuals living with HIV who are unstably housed. AIDS Behav 2011;15:1612-22.

$29 \mathrm{Ti} \mathrm{L}$, Dong H, Kerr T, et al. The effect of engagement in an HIV/AIDS integrated health programme on plasma HIV-1 RNA suppression 
among HIV-positive people who use illicit drugs: a marginal structural modelling analysis. HIV Med 2017;18:580-6.

30 Bowen EA, Canfield J, Moore S, et al. Predictors of CD4 health and viral suppression outcomes for formerly homeless people living with HIV/AIDS in scattered site supportive housing. AIDS Care 2017;29:1458-62.

31 Hall G, Singh T, Lim SW. Supportive housing promotes AIDS-Free survival for chronically homeless HIV positive persons with behavioral health conditions. AIDS Behav 2019;23:776-83.

32 Sadowski LS, Kee RA, VanderWeele TJ, et al. Effect of a housing and case management program on emergency department visits and hospitalizations among chronically ill homeless adults: a randomized trial. JAMA 2009;301:1771-8.

33 Haddad N, Robert A, Weeks A, et al. Hiv in Canada-Surveillance report, 2018. Can Commun Dis Rep 2019;45:304-12.

34 Saskatchewan Ministry of Health. Hiv prevention and control report, 2018, 2018. Available: https://www.saskatchewan.ca/government/ government-structure/ministries/health/other-reports/annual-reportarchive [Accessed 27th Jul 2020].

35 Public Health Agency of Canada. Hiv/Aids EPI update- chapter 1 : national HIV prevalence and incidence estimates for 2011, 2015. Available: https://www.canada.ca/content/dam/phac-aspc/migration/ phac-aspc/aids-sida/publication/epi/2010/pdf/EN_Chapter1_Web. pdf [Accessed 27th Jul 2020].

36 Kelly-Scott K, Smith K. Aboriginal peoples: fact sheet for Canada. 2015. Available: https://www150.statcan.gc.ca/n1/pub/89-656-x/89656-x2015001-eng.pdf [Accessed 27th Jul 2020].

37 Statistics Canada. Focus on geography series, 2016 census: Canada, 2017a. Available: https://www12.statcan.gc.ca/censusrecensement/2016/as-sa/fogs-spg/Facts-CAN-eng.cfm?Lang=Eng\& GK $=$ CAN\&GC $=01 \&$ TOPIC $=9$ [Accessed 27th Jul 2020].

38 Statistics Canada. Focus on geography series, 2016 census: Province of Saskatchewan, 2017b. Available: https://www12.statcan. gc.ca/census-recensement/2016/as-sa/fogs-spg/Facts-PR-Eng. $\mathrm{cfm}$ ?TOPIC=9\&LANG=Eng\&GK=PR\&GC=47 [Accessed 27 th Jul 2020].

39 Government of Canada. Canadian alcohol and drug use monitoring survey. 2014. Available: https://www.canada.ca/en/health-canada/ services/health-concerns/drug-prevention-treatment/drug-alcoholuse-statistics/canadian-alcohol-drug-use-monitoring-surveysummary-results-tables-2012.html\#t2 [Accessed 17th Feb, 2021].

40 Pawson R, Tilley N. Realist evaluation. 2004. Available: http://www. communitymatters.com.au/RE_chapter.pdf [Accessed 12th May 2020].

41 Mukumbang FC, Van Belle S, Marchal B, et al. Realist evaluation of the antiretroviral treatment adherence Club programme in selected primary healthcare facilities in the metropolitan area of Western Cape Province, South Africa: a study protocol. BMJ Open 2016;6:1-11.

42 Mukumbang FC, Van Belle S, Marchal B, et al. An exploration of group-based HIV/AIDS treatment and care models in sub-Saharan Africa using a realist evaluation (Intervention-Context-ActorMechanism-Outcome) heuristic tool: a systematic review. Implement Sci 2017;12:1-20.

43 Mukumbang FC, Marchal B, Van Belle S, et al. A realist approach to eliciting the initial programme theory of the antiretroviral treatment adherence Club intervention in the Western Cape Province, South Africa. BMC Med Res Methodol 2018;18:47.

44 Pawson R, Tilley N. Realistic evaluation. Thousand Oaks, Ca: SAGE Publications, 1997.

45 Jagosh J, Macaulay AC, Pluye P, et al. Uncovering the benefits of participatory research: implications of a realist review for health research and practice. Milbank Q 2012;90:311-46.

46 Dalkin SM, Greenhalgh J, Jones D, et al. What's in a mechanism? Development of a key concept in realist evaluation. Implementation Sci 2015;10:1-7.

47 Bunge M. Mechanism and explanation. Philos Soc Sci 1997;27:410-65.

48 Sayer A. Realism and social science. Thousand Oaks, Ca: SAGE Publications, 2000: 10-28

49 Astbury B, Leeuw FL. Unpacking black boxes: mechanisms and theory building in evaluation. American Journal of Evaluation 2010;31:363-81.

50 Mukumbang FC, Van Belle S, Marchal B, et al. An exploration of group-based HIV/AIDS treatment and care models in subSaharan Africa using a realist evaluation (Intervention-Context-
Actor-Mechanism-Outcome) heuristic tool: a systematic review. Implementation Sci 2017;12:1-20.

51 Danermark B, Ekstrom M, Jakobsen L. Explaining Society: critical realism in the social sciences. London: Routledge, 2002.

52 Rush B, Ogborne A. Program logic models: expanding their role and structure for program planning and evaluation. Can J Program Eval 1991;6:95-106.

53 Perkins DD, Zimmerman MA. Empowerment theory, research, and application. Am J Community Psychol 1995;23:569-79.

54 Zimmerman M. Empowerment theory. In: Rappaport J, Seidman E, eds. Handbook of community psychology. New York, NY: Kluwer Academic/Plenum Publishers, 2000: 43-63.

55 Bandura A. Self-Efficacy: toward a unifying theory of behavioral change. Psychol Rev 1997;84:191-215.

56 Fisher JD, Fisher WA. Changing AIDS-risk behavior. Psychol Bull 1992;111:455-74.

57 Fisher JD, Fisher WA, Williams SS, et al. Empirical tests of an information-motivation-behavioral skills model of AIDS-preventive behavior with gay men and heterosexual university students. Health Psychol 1994;13:238-50.

58 Glaser BG, Strauss AL. The discovery of grounded theory: strategies for qualitative research. Chicago: Aldine, 1967.

59 Low J. A pragmatic definition of the concept of theoretical saturation. Sociol Focus 2019;52:131-9.

60 Manzano A. The craft of interviewing in realist evaluation. Evaluation 2016;22:342-60.

61 Mukumbang FC, Marchal B, Van Belle S, et al. Using the realist interview approach to maintain theoretical awareness in realist studies. Qualitative Research 2020;20:485-515.

62 Kovach M. Indigenous Methodologies [Kobo book]. Toronto: University of Toronto Press, 2009.

63 Nabigon H, Hagey R, Webster S. The learning circle as a research method: the trickster and the windigo in research. Native Social Work Journal 1999;2:113-37.

64 Tachine AR, Yellow Bird E, Cabrera NL. Sharing circles: an Indigenous methodological approach for researching with groups of Indigenous peoples. Int Rev Qual Res 2016:9:277-95.

65 Cyr J. Focus groups for the social science researcher [ebook]. Cambridge University Press, 2019.

66 Parker A, Tritter J. Focus group method and methodology: current practice and recent debate. International Journal of Research \& Method in Education 2006;29:23-37.

67 Gilmore B, McAuliffe E, Power J, et al. Data analysis and synthesis within a realist evaluation: toward more transparent methodological approaches. International Journal of Qualitative Methods 2019;18:160940691985975-11.

68 Dalkin S, Forster N, Hodgson P, et al. Using computer assisted qualitative data analysis software (CAQDAS; NVivo) to assist in the complex process of realist theory generation, refinement and testing. Int J Soc Res Methodol 2021;24:123-34.

69 Henson $\mathrm{H}$. Data quality evaluation for program Evaluators. CJPE 2016;31:99-108.

70 Wong G, Westhorp G, Manzano A, et al. RAMESES I| reporting standards for realist evaluations. BMC Med 2016;14:1-18.

71 Vareilles G, Pommier J, Kane S, et al. Understanding the motivation and performance of community health volunteers involved in the delivery of health programmes in Kampala, Uganda: a realist evaluation protocol. BMJ Open 2015;5:e006752.

72 Marchal B, van Belle S, van Olmen J, et al. Is realist evaluation keeping its promise? A review of published empirical studies in the field of health systems research. Evaluation 2012;18:192-212.

73 Rycroft-Malone J, Fontenla M, Bick D, et al. A realistic evaluation: the case of protocol-based care. Implement Sci 2010;5:38.

74 Fick F, Muhajarine N. First steps: creating an initial program theory for a realist evaluation of healthy Start-Départ Santé intervention in childcare centres. Int J Soc Res Methodol 2019:1-12.

75 Goodridge D, Westhorp G, Rotter T, et al. Lean and leadership practices: development of an initial realist program theory. BMC Health Serv Res 2015;15:362.

76 Shearn K, Allmark P, Piercy H, et al. Building realist program theory for large complex and messy interventions. International Journal of Qualitative Methods 2017;16:160940691774179-11.

77 Nurjono M, Shrestha P, Lee A, et al. Realist evaluation of a complex integrated care programme: protocol for a mixed methods study. BMJ Open 2018;8:e017111. 